\title{
Should Scientists Embrace Scientific Realism or Antirealism?
}

\begin{abstract}
If scientists embrace scientific realism, they can use a scientific theory to explain and predict observables and unobservables. If, however, they embrace scientific antirealism, they cannot use a scientific theory to explain observables and unobservables, and cannot use a scientific theory to predict unobservables. Given that explanation and prediction are means to make scientific progress, scientists can make more scientific progress, if they embrace scientific realism than if they embrace scientific antirealism.
\end{abstract}

\section{Keywords}

Scientific Antirealism, Scientific Progress, Scientific Realism, Moore's Paradox

Park, Seungbae (2018). "Should Scientists Embrace Scientific Realism or Antirealism?" Philosophical Forum (to be assigned).

Seungbae Park

Ulsan National Institute of Science and Technology

Republic of Korea

nature@unist.ac.kr

\section{Introduction}

This paper concerns the two kinds of scientific progress: theoretical and empirical. ${ }^{1}$ Science makes theoretical progress when a new theory comes closer to the truth than an old theory, and empirical progress when a new theory comes closer to empirical adequacy than an old theory. $\mathrm{T}_{1}$ is closer to empirical adequacy than $\mathrm{T}_{2}$, for example, if $90 \%$ and $80 \%$ of the observational consequences of $\mathrm{T}_{1}$ and $\mathrm{T}_{2}$ are true, respectively. An interesting question arises: Should scientists be scientific realists or antirealists in order to make theoretical and empirical progress?

We conduct cost-benefit analyses in our daily lives when we face two competing courses of action. Suppose, for example, that we have the goal of having fun over the weekend by going on a trip, and that we have the option of going to Las Vegas and the option of going to the Grand Canyon. In such a situation, we perform the cost-benefit analyses of the two options, i.e., we imagine what the costs and benefits of going to Las Vegas and to the Grand Canyon would be. After comparing the costs and benefits, we make a final judgment about whether to go to Las Vegas or to the Grand Canyon. To say that we should choose Las Vegas over the Grand Canyon means that the net benefit of going to Las Vegas outweighs that of going to the Grand Canyon.

Similarly, suppose that scientists have the goal of making scientific progress, i.e., that they have the goal to be closer to truths and empirical adequacy than before. Should they be realists or antirealists? To answer this question, they should conduct cost-benefit analyses of being realists and of being antirealists, i.e., they should imagine what the costs and the benefits of being realists and of being antirealists would be. After comparing the costs and the benefits, they should make the final judgment about whether to be realists or antirealists. This paper focuses on epistemic costs and benefits, aiming to show that scientists should embrace realism over antirealism, i.e., that the net epistemic benefit of being realists outweighs that of

\footnotetext{
${ }^{1}$ This paper does not address methodological progress, given that the relevant discourse about it can be extrapolated from the present discourse about empirical progress.
} 
being antirealists.

My discussion proceeds as follows. In Section 2, I display the costs and the benefits of the important versions of realism and antirealism vis-à-vis scientific revolutions, arguing that realists have no more reason to resist scientific revolutions than antirealists, and vice versa. In Section 3, I apply the cost-benefit analyses to the debate between Ernst Mach (1838-1916) and Max Planck (1858-1947) over whether scientists should be realists or instrumentalists. I argue that Mach overlooked what realists gain from scientific revolutions, and that Planck overlooked what instrumentalists gain. In Section 4, I provide reasons for thinking that realism is more effective for achieving scientific progress than antirealism is, and hence that scientists should choose realism over antirealism.

This paper operates under the following two assumptions: First, there will be scientific revolutions, as there were before the early twentieth century. This assumption is controversial. P. Kyle Stanford (2006: 19-20) and K. Brad Wray (2013: 4329) affirm it. By contrast, Seungbae Park (2016a) denies it, arguing that scientific revolutions will be rare as in the twentieth century. Second, new theories are closer to truths and empirical adequacy than old theories. So science progresses through scientific revolutions. This assumption is also controversial. While Wray (2007: 86) denies it, Moti Mizrahi (2013), Seungbae Park (2014a: 270), and Juha Saatsi (2015) affirm it. The main thesis of this paper would collapse without these two assumptions. Any objection that readers will raise against them should be addressed in separate papers.

\section{Cost-Benefit Analyses}

\subsection{Truth vs. Empirical Adequacy}

Suppose that realism and antirealism are defined as the views, respectively, that successful theories are true ${ }^{2}$ and empirically adequate. ${ }^{3}$ So before scientific revolutions, realists believed that old theories were true. After scientific revolutions, they believe that the old theories were false, and that the new theories are true. Analogously, before scientific revolutions, antirealists believed that old theories were empirically adequate. After scientific revolutions, they believe that the old theories were empirically inadequate, and that the new theories are empirically adequate.

Under this condition, who would be more motivated to welcome scientific revolutions? To answer this question, we need to consider what realists and antirealists lose and gain as a result of scientific revolutions. Realists lose their old belief that old theories were true, but they get new theories which are closer to truths and empirical adequacy than the old theories, i.e., they gain both theoretical and empirical progress. In contrast, antirealists lose their old belief that old theories were empirically adequate, but they get new theories which are closer to empirical adequacy than the old theories, i.e., they gain empirical progress. To put it roughly, after a scientific revolution, realists lose a lot but gain a lot, while antirealists lose a little but gain a little. Therefore, it is not clear who would be more motivated to resist scientific revolutions.

Antirealists might contend that it is better to lose a little and gain a little than to lose a lot and gain a lot. Epistemic security is more important than anything else, so a big loss outweighs a big gain, a small loss also outweighs a small gain, and even a small loss

\footnotetext{
${ }^{2}$ Extensional realists (Park, 2016b: 47) believe that a scientific theory is true, once they think that scientists' arguments for it are strong.

${ }^{3}$ Bas van Fraassen (1985: 294) and Wray (2008: 321; 2012: 376) claim that successful theories are empirically adequate. Mario Alai interprets constructive empiricism as claiming that "all we need to believe is that a theory is empirically adequate" (2017: 21).
} 
outweighs a big gain. Realists have no theoretical resource to persuade antirealists.

Consider, however, that Cartesian skeptics can raise the same objection to antirealists. Cartesian skeptics believe that none of what successful theories say about the world is worthy of our beliefs. They argue that epistemic security is more important than anything else, so it is better to lose nothing and gain nothing than to lose a little and gain a little. Antirealists have no theoretical resource to persuade Cartesian skeptics.

A moral is that it is merely a matter of taste whether one chooses to lose a lot and gain a lot, or chooses to lose a little and gain a little. No rational argumentation can persuade realists or antirealists one way or the other. If realists and antirealists claim that their position is better than that of their opponents, they are merely expressing their different tastes.

A referee raises the following interesting issue. Von Neumann and Dirac's version of Copenhagen interpretation of quantum mechanics competes with many-worlds interpretation and Bohmian mechanics. The three competitors make radically distinct claims about unobservables but the same claims about observables. Realists should demonstrate the superiority of one competitor over the others before they believe that it is true. By contrast, antirealists do not have to because they only believe that the observational claims of the three competitors are true. Which of the three competitors should realists choose?

The aim of this paper is not to solve the problem of underdetermination in quantum mechanics but to establish the modest thesis that realism is a better means than antirealism for making scientific progress. The modest thesis does not require that realists should adjudicate among the three competitors. Consider that antirealists should also choose one among the three rivals to make predictions about observables. If they choose von Neumann and Dirac's version and then believe that it is empirically adequate, realists can also choose it and then believe that it is true. Of course, the realist belief is more likely to be false than the antirealist belief. But the main thesis of this section remains unscathed that realists are no less favorable than antirealists to the scientific revolution that will oust all the three competitors.

\subsection{Approximate Truth vs. Approximate Empirical Adequacy}

Suppose that realists and antirealists believe, respectively, that successful theories are approximately true and approximately empirically adequate. A theory is approximately empirically adequate when most of its observational consequences are true (Park, 2009: 117, footnote). Realists and antirealists might retreat to approximate truth and approximate empirical adequacy, respectively, in response to the pessimistic induction, which maintains that since past theories turned out to be false and empirically inadequate, present theories will also turn out to be false and empirically inadequate (Poincaré, 1905/1952: 160; Mach, 1911: 17; Laudan 1977: 126; Putnam, 1978: 25).

Before scientific revolutions, realists believed that old theories were approximately true. After scientific revolutions, they believe that both old and new theories are approximately true, but that the new theories are closer to truths and empirical adequacy than the old theories were. Similarly, before scientific revolutions, antirealists believed that old theories were approximately empirically adequate. After scientific revolutions, they believe that both old and new theories are approximately empirically adequate, and that the new theories are closer to empirical adequacy than the old theories were.

Is it possible to believe that both old and new theories are approximately true, and that the new theories are closer to truths than the old theories were? Wray (2008: 323) and Mizrahi (2013: 401) would say yes. They distinguish between being close to the truth and being closer to the truth than a competitor. Their distinction can be illuminated with the following analogy. Suppose that you and I are in a marathon race from Paris to Berlin, that you and I are almost in Berlin, and that you are one step ahead of me. In such a situation, you 
and I are both close to Berlin, but you are closer to Berlin than I am. Similarly, it is possible that both $T_{1}$ and $T_{2}$ are close to the truth, i.e., they are both approximately true, and yet $T_{1}$ is closer to the truth than $T_{2}$ is. It is not the case that if both $T_{1}$ and $T_{2}$ are approximately true, $T_{1}$ cannot be closer to the truth than $\mathrm{T}_{2}$ is. Analogously, it is possible that both old and new theories are approximately empirically adequate, and that the new theories are closer to empirical adequacy than the old theories were.

Under this condition, who would be more open-minded to new theories? Again, to answer this question, we need to examine what realists and antirealists lose and gain as a result of scientific revolutions. Realists have nothing to lose. As Philip Kitcher (1993: 140 149) and Stathis Psillos (1999: 113) argue, some theoretical constituents of past theories were carried over to present theories after scientific revolutions, so past theories can be said to be approximately true. Their position is called 'selective realism' and 'preservative realism' in the literature. Thus, realists can retain their belief that old theories were approximately true. Antirealists have nothing to lose either. The fact that the phlogiston theory and the caloric theory clashed with empirical anomalies does not refute the weak position that they are approximately empirically adequate, although it does refute the strong position that they are empirically adequate. Thus, antirealists can retain their old belief that old theories were approximately empirically adequate. Now, who gains more from scientific revolutions? Realists gain both theoretical and empirical progress, whereas antirealists gain only empirical progress. It follows that overall, realists have a stronger reason for supporting scientific revolutions than antirealists do.

\subsection{Truth vs. Usefulness}

Suppose that realists believe that successful theories are true, and that instrumentalists believe that they are useful. ${ }^{4}$ On the instrumentalist account, successful theories "are simply tools or instruments for making empirical predictions and achieving other practical ends" (Stanford, 2006: 189). Instrumentalists do not believe that successful theories are true, although they believe that the observational consequences of successful theories are true.

Before we compare the advantages and disadvantages of realism with those of instrumentalism, we need to be clear about what exactly instrumentalists are committed to. They are committed either to the view that successful theories are empirically adequate or to the view that they are approximately empirically adequate. They cannot hold the view that successful theories are less than approximately empirically adequate. After all, if most of the observational consequences of a theory are false, it is not clear how it can be useful for making predictions and manipulations.

Under this condition, who would be more receptive to new theories? Suppose that instrumentalists are committed to the position that successful theories are empirically adequate. It is not clear whether instrumentalists would be more supportive of scientific revolutions than realists, as we have already seen in Section 2.2. Realists lose a lot but gain a lot, whereas instrumentalists lose a little but gain a little from scientific revolutions. Suppose that instrumentalists are committed to the position that successful theories are approximately empirically adequate. It is not clear either who would be more open-minded to new theories. Realists lose their old belief that old theories were true. Instrumentalists do not lose their old belief that old theories were approximately empirically adequate. But realists gain both theoretical and empirical progress. Instrumentalists gain only empirical progress. It is not clear how we can compare the weight of the realist loss of their belief with the weight of the

\footnotetext{
${ }^{4}$ Stanford (2006: 195) embraces epistemic instrumentalism.
} 
instrumentalist failure to gain theoretical progress.

In sum, it does not matter whether instrumentalists are committed to the position that successful theories are empirically adequate or to the position that they are approximately empirically adequate. It is difficult to determine who would be more motivated to welcome or unwelcome scientific revolutions.

\section{Debate between Mach and Planck}

This section applies the preceding cost-benefit analyses to the debate between Mach and Planck over whether realism or instrumentalism was better for scientific progress. Mach maintained that instrumentalism is more beneficial to scientific progress; Planck maintained that realism is more beneficial to scientific progress. The cost-benefit analyses indicate, however, that their arguments are all flawed, as will become clear in this section.

Mach accused realism of hindering the advent of new theories. He observed that realists are dogmatic about old theories and hesitant to entertain new theories. He says that whoever "knows only one view or one form of a view does not believe that another has ever stood in its place, or that another will ever succeed it; he neither doubts nor tests" (Mach, 1911: 17). In short, realism has the disadvantage of impeding scientific revolutions by making scientists believe that old theories are true.

In my view, however, we should expose the advantage, as well as the disadvantage, of realism. The advantage of realism is that as a result of scientific revolutions, scientists are closer to truths than before. In addition, we should compare the advantage and the disadvantage of realism with those of instrumentalism before we make the final choice between realism and instrumentalism. Instrumentalism has an advantage, viz., as a result of scientific revolutions, scientists are closer to empirical adequacy than before. But it has a disadvantage, viz., as a result of scientific revolutions, scientists lose their old belief that old theories are empirically adequate. Again, realism makes scientists lose a lot but gain a lot, whereas instrumentalism makes scientists lose a little but gain a little. Given this cost-benefit analysis of realism and instrumentalism, it is not clear which is better in terms of making scientists open-minded.

Mach might reply that instrumentalists believe that successful theories are not empirically adequate but approximately empirically adequate. So they do not lose their belief that old theories are approximately empirically adequate. Realists would reply, however, that they believe that successful theories are not true but approximately true. So they do not lose their belief either that old theories are approximately true. Hence, retreating to approximate empirical adequacy does not make instrumentalism more congenial than realism to the advent of new theories.

Planck accused instrumentalism of making scientists complacent, saying that "the physicist, if he wants to promote science, has to be a realist, not an economizer" (Planck, 1910/1992, 146). His idea is that instrumentalists do not care whether theories are true or false. They only care whether theories make true predictions or not. So they are content insofar as theories make true predictions, and they do not bother to replace old theories with new theories with the view to better representing unobservables. Only realists make such efforts.

Planck's criticism against instrumentalism is unfair for the following reason. The history of science tells us that theories have been getting closer and closer to empirical adequacy through scientific revolutions. New theories have broader predictive scopes than old theories. As a result, instrumentalists would not settle for old theories, even if they are useful to a certain extent. They would be in search of more useful theories, which make more true predictions than old theories. In short, empirical progress motivates instrumentalists to 
replace old theories with new ones.

In sum, Mach overlooked what realists gain from scientific revolutions, viz., theoretical progress, while Planck overlooked what instrumentalists gain from scientific revolutions, viz., empirical progress. Neither of them compared both the advantage and the disadvantage of his own position with those of his opponent's position. If they had conducted thorough cost-benefit analyses of both realism and instrumentalism, they would not have attacked each other's positions as they did.

\section{Explanation and Prediction}

The cost-benefit analyses of realism and antirealism show that it is not clear which position is more beneficial to scientific progress. The debate between Mach and Planck does not decide this issue. This section aims to tip the scale in favor of realism by invoking the advantages of realism over antirealism concerning explanation and prediction.

Realists believe, but antirealists do not, for example, that the standard model of particle physics is (approximately) true. According to the standard model, macro objects like stones and trees are composed of atoms. An atom is made up of protons, neutrons, and electrons. Protons and neutrons can be further broken down into quarks. All these particles have mass. But why do they have mass? The standard model says that they have mass because they interact with the Higgs field. If the Higgs field were turned off, they would become massless and move at the speed of light. Thus, the Higgs field is what makes them have mass, slow down, and form atoms.

Imagine that antirealists say, "A stone has mass because it interacts with the Higgs field, but I don't believe a stone interacts with the Higgs field." They say, "A stone has mass because it interacts with the Higgs field" to explain why a stone has mass. They add, "I don't believe a stone interacts with the Higgs field" to express their antirealist commitment that unobservables, including the Higgs field, are not worthy of our belief. Their sentence, however, sounds odd. Why does it sound odd? It involves Moore's paradox. Moore's paradox occurs when we say any sentence that takes the form, "P, but I don't believe p" or "P, but I believe not p" (Moore, 1993: 207-212).

Moore's paradox stems from the gap between what we speak and what we believe (Park, 2014b). Antirealists say, "A stone has mass because it interacts with the Higgs field," when they do not believe that a stone has mass because it interacts with the Higgs field. Their speech act does not match up with their doxastic state. So they are caught in Moore's paradox. By contrast, realists' speech act matches up with their doxastic state. They say, "A stone has mass because it interacts with the Higgs field" in accordance with their belief that a stone has mass because it interacts with the Higgs field. So they are free from Moore's paradox (Park, 2016c: 77-78). Suppose that antirealists say, "A stone has mass because it interacts with the Higgs field," but they do not declare to their audience that they do not believe that a stone has mass because it interacts with the Higgs field. In such a case, their audience may ask them disconcerting questions: "Do you believe what you just said? If you don't, why should I believe what you don't? How can you say to me what you don't believe? Do you expect me to believe what you don't?" Antirealists owe us answers to these questions.

Antirealists run into Moore's paradox or the disconcerting questions not only when they explain observables but also when they explain unobservables. Consider the explanation that a proton has mass because it interacts with the Higgs field. The explanandum - a proton has mass - is not observable. Antirealists cannot explain such an explanandum due to Moore's paradox and the disconcerting questions.

Set aside these problems. Antirealists would not bother to explain why an unobservable 
fact is as a scientific theory says it is, for their beliefs are restricted to observables. They would think that it is a waste of time to ask and explain why a proton has mass, just as you would think that it is a waste of time to ask and explain why a unicorn has one horn as opposed to two horns, if you believe that a unicorn does not exist. In general, we do not take an explanation seriously, if we do not believe that its explanandum exists.

Let me turn to the issue of prediction. Moore's paradox does not arise when antirealists predict an observable fact, but it arises when they predict an unobservable fact. The standard model predicts that if the Higgs field were turned off, a stone and a proton would become massless and their constituent particles would travel at the speed of light. Antirealists can say, "If the Higgs field were turned off, a stone would become massless." Such a prediction does not require that antirealists believe that the standard model is true. But how about the prediction that if the Higgs field were turned off, a proton would become massless? This prediction is not a prediction of an observable fact but a prediction of an unobservable fact. Antirealists cannot give such a prediction, for they would be caught in Moore's paradox. They would have to say, "If the Higgs field were turned off, a proton would become massless, but I don't believe if the Higgs field were turned off, a proton would become massless."

In response, antirealists might appeal to van Fraassen's (1980) distinction between belief and acceptance. According to him, antirealists do not believe T, but they accept T. They do not believe, for example, that if the Higgs field were turned off, a proton would become massless, but they accept that if the Higgs field were turned off, a proton would become massless. So it is legitimate for antirealists to say, "If the Higgs field were turned off, a proton would become massless." In short, antirealists can talk as if they are realists because they accept T. It appears therefore that van Fraassen's notion of acceptance enables antirealists to predict an unobservable fact by invoking another unobservable fact.

It is not clear, however, whether van Fraassen's distinction between belief and acceptance is tenable or not. Van Fraassen claims that there is a mental difference between realists who believe $\mathrm{T}$ and antirealists who accept $\mathrm{T}$. The mental difference is that realists believe that $\mathrm{T}$ is true, while antirealists believe that it is empirically adequate. There is, however, no verbal difference between them, i.e., antirealists talk exactly as realists do, as we noted above. However, the absence of the verbal difference between them gives rise to the suspicion that there is no mental difference between them either, i.e., antirealists believe $\mathrm{T}$, as realists do. In other words, if antirealists say everything that realists say and vice versa, we have no reason for thinking that the putative mental difference between them exists. Thus, antirealists have the burden to flesh out a non-mental difference between realists and antirealists that stems from the alleged mental difference between them. In other words, they need to make it explicit what it is that realists can do but antirealists cannot due to the fact that realists believe $\mathrm{T}$ while antirealists accept $\mathrm{T}$.

Even if antirealists successfully cash out a non-mental difference between realists and antirealists, they cannot still escape from Moore's paradox. Imagine that antirealists accept the standard model and then say, "(1) If the Higgs field were turned off, a proton would become massless, (2) but I don't believe if the Higgs field were turned off, a proton would become massless, (3) but I accept if the Higgs field were turned off, a proton would become massless." Antirealists say (1) to make the prediction and (2) to express antirealism. Note that they are caught in Moore's paradox. Therefore, it does not matter whether van Fraassen's notion of acceptance is coherent or not. Antirealists are not free from Moore's paradox. ${ }^{5}$

\footnotetext{
${ }^{5}$ See Park (2015: 227, 2017: 60) for other critical responses to antirealists who appeal to van Fraassen's distinction between belief and acceptance in order to avoid Moore's paradox and the disconcerting questions.
} 
Explanatory power and predictive power are virtues of scientific theories that scientists use to choose a theory over its competitors. Other things being equal, scientists choose $\mathrm{T}_{1}$ over $T_{2}$, if $T_{1}$ has higher explanatory power or predictive power than $T_{2}$. The discussion above shows, however, that Moore's paradox or the disconcerting questions prevent antirealists from using scientific theories to explain observables and unobservables, and to predict unobservables. So if scientists embrace realism over antirealism, they can fully use explanations and predictions as means to make scientific progress. By contrast, if they embrace antirealism, they cannot.

Antirealists might object that I have appealed to explanatory power and predictive power to support realism, thereby begging the question against them. One of the key disagreements between realists and antirealists is whether explanations and predictions can provide warrant for a theory. Realists say yes; antirealists say no. I cannot resolve the dispute between them by appealing to the realist position.

The preceding objection, however, commits the straw man fallacy. Nowhere does this paper assume that explanations and predictions provide warrant for a theory. This paper only assumes that when $T_{1}$ explains or predicts more phenomena than $T_{2}$, we are justified in believing that $T_{1}$ is closer to the truth than $T_{2}$, while remaining neutral as to whether we are justified in believing that $T_{1}$ is (approximately) true. Recall that I stated in Section 1 that this paper operates under the assumption that new theories are closer to truths than old theories.

This modest assumption is very different from the ambitious assumption that new theories are (approximately) true, as Wray (2008: 323) and Mizrahi (2013: 401) observe. To use the analogy in Section 2.2, you can be closer to Berlin than I am, even if you are far from Berlin. So it is one thing to say that new theories are (approximately) true; it is quite another to say that new theories are closer to truths than old theories. Even if we grant for the sake of argument that antirealists have demolished the former thesis in the literature, it does not follow that they have thereby demolished the latter thesis. It is much harder to refute the latter thesis than the former thesis.

\section{Conclusion}

If realists were more motivated to welcome scientific revolutions than antirealists, realism would be the better means to achieve scientific progress than antirealism, and scientists would have to be realists. By contrast, if antirealists were more motivated to welcome scientific revolutions than realists, antirealism would be the better means to achieve scientific progress than realism, and scientists would have to be antirealists.

The cost-benefit analyses of realism and antirealism show, however, that realists lose a lot but gain a lot, while antirealists lose a little but gain a little, as a result of scientific revolutions. Hence, it is hard to tell who would be more motivated to welcome scientific revolutions, and the cost-benefit analyses do not yield guidance as to whether scientists should be realists or antirealists.

The examination of the doxastic requirement of scientific explanation and prediction shows, however, that realists can use a scientific theory to explain and predict both observables and unobservables. By contrast, antirealists cannot use a scientific theory to explain something, whether that thing is observable or unobservable. Nor can they use a scientific theory to predict unobservables. They can only use it to predict observables. For this reason, realism is a better means than antirealism for scientists to make scientific progress. In sum, I believe more. Therefore, I progress more.

\section{References}


Alai, Mario (2017). "The Debates on Scientific Realism Today: Knowledge and Objectivity in Science", In Varieties of Scientific Realism: Objectivity and Truth in Science. Evandro Agazzi (ed.), Switzerland: Springer International Publishing, 19-47.

Kitcher, Philip (1993). The Advancement of Science: Science without Legend, Objectivity without Illusion. New York: Oxford University Press.

Laudan, Larry (1977). Progress and Its Problems: Towards a Theory of Scientific Growth. California: University of California Press.

Mach, Ernst (1911). History and Root of the Principle of the Conservation of Energy (Jourdain P. E. B., Trans.). Chicago: Open Court Publishing Company.

Mizrahi, Moti (2013). "The Argument from Underconsideration and Relative Realism", International Studies in the Philosophy of Science. 27 (4): 393-407.

Moore, George (1993). "Moore's Paradox", In G.E. Moore: Selected Writings. Baldwin, Thomas (ed.), London: Routledge.

Park, Seungbae (2009). "Philosophical Responses to Underdetermination in Science", Journal for General Philosophy of Science 40 (1): 115-124.

(2014a). "On the Evolutionary Defense of Scientific Antirealism", Axiomathes 24 (2): 263-273.

(2014b). "On the Relationship between Speech Acts and Psychological States", Pragmatics and Cognition 22 (3): 340-351.

$218-227$.

(2015). "Accepting Our Best Scientific Theories", Filosofija. Sociologija 26 (3):

(2016a). "Why Should We Be Pessimistic about Antirealists and Pessimists?" Foundations of Science. doi:10.1007/s10699-016-9490-y.

(2016b). "Extensional Scientific Realism vs. Intensional Scientific Realism," Studies in History and Philosophy of Science 59: 46-52.

(2016c). "Scientific Realism and Antirealism in Science Education", Coactivity: Philosophy. Communication. 24 (1): 72-81.

-------- (2017). “Defense of Epistemic Reciprocalism”, Filosofija. Sociologija 28 (1): 5664.

Planck, Max (1910/1992). “On Mach's Theory of Physical Knowledge - A Reply”, In Ernst Mach - A Deeper Look: Documents and New Perspectives. John Blackmore (ed.), Dordrecht: Kluwer Academic Publishers.

Poincaré, Henri (1905/1952). Science and Hypothesis. New York: Dover. 
Psillos, Stathis (1999). Scientific Realism: How Science Tracks Truth. New York: Routledge.

Putnam, Hilary (1978). Meaning and the Moral Sciences. London: Routledge \& K. Paul.

Saatsi, Juha (2015). "Historical Inductions, Old and New", Synthese. doi:10.1007/s11229015-0855-5

Stanford, P. Kyle (2006). Exceeding Our Grasp: Science, History, and the Problem of Unconceived Alternatives. Oxford: Oxford University Press.

Bas van Fraassen (1980). The Scientific Image. Oxford: Oxford University Press.

(1985). "Empiricism in the Philosophy of Science" In Images of Science. P. Churchland and C. Hooker (eds.), Chicago: University of Chicago Press.

Wray, K. Brad (2007). "A Selectionist Explanation for the Success and Failures of Science”, Erkenntnis 67 (1): 81-89.

(2008). "The Argument from Underconsideration as Grounds for Anti-Realism: A Defence", International Studies in the Philosophy of Science 22 (3): 317-326.

--------- (2012). "Epistemic Privilege and the Success of Science”, Noûs 46 (3): 375-385.

(2013). "Pessimistic Induction and the Exponential Growth of Science Reassessed", Synthese 190 (18): 4321-4330. 